\title{
Continuidad neoliberal vía tecnocracia: las comisiones asesoras presidenciales para la reforma previsional en Chile
}

\author{
Neoliberal continuity via technocracy: the presidential advisory \\ commissions for pension reform in Chile \\ Continuidade neoliberal via tecnocracia: as comissões \\ assessoras presidenciais para a reforma da previdência no Chile
}

Camilo Garber*

\section{RESUMEN}

El neoliberalismo se ha mostrado excepcionalmente resiliente en Chile. Un ejemplo conspicuo es el sistema previsional. Por su bajo rendimiento, ha sido objeto de sucesivas críticas e instancias reformistas. El objetivo de este trabajo es mostrar la formación, composición y recomendaciones que surgieron de las Comisiones Asesoras Presidenciales ad hoc de 2006 y 2015. Como caso de estudio en profundidad, se revisa el propósito de su creación, la trayectoria académica de sus integrantes y el alcance transformador de sus recomendaciones. Se constata que ellas funcionan bajo la lógica de la representación política tecnocrática que sustrae una discusión de alta resonancia social de la arena democrática, dentro de un marco de poca representatividad social y con fuerte presencia de economistas. Todo ello limita su alcance transformador. A cambio, se produce una confluencia entre la tecnocracia y el neoliberalismo. Ambos regímenes de poder apuntan a insubordinar la economía respecto de la democracia, otorgando primacía a esquemas de mercado de orientación técnica en la solución de problemas sociopolíticos.
Palabras clave:

comisiones asesoras presidenciales, neoliberalismo, sistema previsional chileno, tecnocracia.

* Chileno. Doctorando en Ciencias Sociales. Universidad Diego Portales. Santiago, Chile.camilo.garber@mail.udp.cl 


\begin{abstract}
Neoliberalism has proved exceptionally resilient in Chile. A conspicuous example is the pension system. Because of its poor performance, it has been the object of successive criticisms and reform efforts. The aim of this paper is to show the formation, composition and recommendations that emerged from the ad hoc Presidential Advisory Commissions of 2006 and 2015. As an in-depth case study, it reviews the purpose of their creation, the academic background of their members and the transformative scope of their recommendations. It is clear that they operate under the logic of technocratic political representation, which removes from the democratic sphere a discussion of high social resonance. It falls into a framework of low social representation and with a strong focus on economists, all of which limits its transformative scope. On the other hand, there is a confluence between technocracy and neoliberalism. Both power regimes aim to insubordinate the economy in terms of democracy, giving primacy to technically oriented market schemes for solving socio-political problems.
\end{abstract}

\section{RESUMO}

O neoliberalismo se mostrou excepcionalmente resistente no Chile. Um exemplo conspícuo é o sistema previdenciário. Devido a seu baixo rendimento, tem sido objeto de sucessivas críticas e instâncias de reforma. O objetivo deste trabalho é mostrar a formação, composição e recomendações que surgiram das Comissões Assessoras Presidenciais ad hoc de 2006 e 2015. Como um estudo de caso aprofundado, é revisto o propósito de sua criação, a trajetória acadêmica de seus membros e o alcance transformador de suas recomendações. Constata-se que operam sob a lógica da representação política tecnocrática que remove uma discussão de alta ressonância social da arena democrática, dentro de uma estrutura de pouca representação social e com uma forte presença de economistas. Tudo isso limita seu alcance transformador. Pelo contrário, existe uma confluência entre a tecnocracia e o neoliberalismo. Ambos os regimes de poder visam insubordinar a economia com respeito à democracia, dando primazia aos esquemas de mercado de orientação técnica na solução dos problemas sociopolíticos.
Keywords: presidential advisory commissions, neoliberalism, Chilean pension system, technocracy.

Palavras-chave: comissões assessoras presidenciais, neoliberalismo, sistema previdenciário chileno, tecnocracia. 


\section{Introducción}

Las ciencias sociales se han ocupado profusamente de estudiar el surgimiento y las primeras experiencias del neoliberalismo (Harvey, 2007; Mirowski y Plehwe, 2009; Valdés, 1995), como un ejemplo de un conjunto de políticas económicas con aspiraciones sistémicas que lograron trascender también hacia la esfera política (Brown, 2015; Foucault, 2008; Laval y Dardot, 2013). En su desarrollo y despliegue histórico, el neoliberalismo ha enfrentado sucesivas instancias de crisis que han puesto a prueba su resiliencia (Crouch, 2011; Streeck 2014). Este fenómeno resulta de creciente importancia en las investigaciones del área, abocadas a distinguir los fundamentos de su fortaleza. Y es que su continuidad se comprende tanto por la hegemonía fáctica de los principios sobre los que se erige (Buchanan, 1979; Friedman, 1951), como por el debilitamiento sistemático de las alternativas prefiguradas (Fisher, 2017; Laclau y Mouffe, 1985).

En este contexto, Chile se instituye en un caso de estudio de particular interés, no solo por haber sido el primer país que acometió reformas estructurales inspiradas en los principios neoliberales (Madariaga, 2020), sino que también por la resiliencia que ha exhibido, logrando proyectarse desde su origen autoritario hasta su consolidación democrática por parte de gobiernos de centro izquierda (Huneeus, 2014; Solimano, 2012; Weyland, 1999).

En efecto, la experiencia política y económica chilena de los últimos cincuenta años está marcada por la revolución capitalista que encabezó el sector civil del régimen autoritario (1973-1990) dirigido por Augusto Pinochet (Gárate, 2012). Liderado por los Chicago Boys, un grupo de tecnócratas neoliberales formados en la Universidad de Chicago bajo la mentoría de Milton Friedman, Gary Becker y Arnold Harberger, entre otros, la gestión económica contempló un plan de reformas estructurales que, en línea con los desarrollos teóricos de la Escuela de Chicago, apuntó a liberalizar radicalmente la economía, rompiendo con un ciclo histórico ligado con el desarrollismo y la escuela cepaliana. Los pilares de esta reforma neoliberal trascendieron el cambio de régimen político en 1990, logrando consolidación y validación social en democracia. Esta característica resulta singular en las experiencias latinoamericanas, en donde las transformaciones de este tipo fueron impulsadas por gobiernos democráticos (Ruiz, 2019; Salazar, 2019). 
Dentro del plan de modernización económica de inspiración neoliberal de la dictadura, se encuentra la reforma del sistema previsional. Sus promotores se encontraban convencidos respecto de que el antiguo esquema no era viable económicamente, principalmente en atención a su mecanismo solidario y al rol garante del Estado (Piñera, 1991). Es así como en un contexto autoritario, sin deliberación pública, se instauró un sistema de pensiones de capitalización individual, sin componentes solidarios ni de redistribución del ingreso, el cual sería administrado por instituciones privadas con fines de lucro (Huneeus, 2016). El papel del Estado sería meramente subsidiario, actuando como una prótesis del mercado, en caso de que las gratificaciones entregadas no cumplieran con un estándar mínimo (Ruiz y Boccardo, 2014). Este modelo fue propuesto para su adopción por parte de las Fuerzas Armadas, quienes no obstante se resistieron y optaron por continuar con su esquema de inspiración solidaria y a cargo del Estado (Gárate, 2012; Rivadeneira, 2017).

El desarrollo histórico democrático del sistema previsional civil no ha estado exento de controversias, especialmente por la baja cuantía de las pensiones entregadas. Si en su origen la proyección consistía en que los trabajadores, luego de cuarenta años de cotizaciones, recibirían una pensión con tasa de reemplazo de 70\%, en el año 2000 la Asociación de Administradoras de Fondos de Pensiones (AAFP) subió su apuesta: en caso de que la rentabilidad de los fondos de previsionales se mantuviera entre el $6 \%$ y $7 \%$, los afiliados pensionarían con el $100 \%$ de su sueldo en 2020 (El Mercurio, 2000). La realidad dista radicalmente de esta proyección. A marzo de 2020, con un promedio de rentabilidad de los fondos de pensiones en torno al 5\% durante los últimos diecisiete años, las pensiones entregadas alcanzan un valor mediano del 62,9\% del salario mínimo, con un 50\% de jubilados recibiendo una pensión que reemplaza solo el $40 \%$ de su última remuneración (Gálvez y Kremerman, 2020).

En consideración de sus exiguos resultados, la ciudadanía se ha expresado de forma sostenida en el tiempo a favor de introducir reformas en el esquema previsional. De acuerdo con los estudios de Latinobarómetro, en 1995 un 79\% de los chilenos prefería que el Estado participase en la administración de las pensiones, cifra que se alza hasta el 91\% en el año 2017 (Latinobarómetro, 1998, 2017). Un fenómeno con- 
comitante con este cuadro consiste en la formación en junio de 2013, e irrupción en la arena política el 2016, de la Coordinadora $N o+A F P$. Ella, que constituye una forma de expresión de movimiento social, articuló a una serie de agrupaciones de la sociedad civil en contra del actual sistema previsional de capitalización individual, de administración privada y con fines de lucro, apostando a transitar hacia un esquema de reparto universal, tripartito y público (Olivares y Carrasco, 2020; Rozas y Maillet, 2019).

Por su parte, en el marco del estallido social de octubre de 2019, que puede ser entendido a modo de una impugnación al neoliberalismo chileno (Akram, 2020; Ruiz, 2020), un 51\% de preferencias consigna la reforma al sistema de pensiones como la primera medida que contribuiría a solucionar el conflicto (Espacio Público-IPSOS, 2019). Frente a la crisis económica producida por la pandemia Covid-19 en Chile, en una medida sin precedentes, con amplio apoyo ciudadano ${ }^{1}$ y en el Congreso $^{2}$, se aprobó el retiro de hasta el $10 \%$ de los fondos previsionales de los afiliados a las AFP.

Resulta relevante destacar que tanto las bajas pensiones que entrega este sistema, como la sostenida inconformidad ciudadana, han sido reconocidos por los gobiernos democráticos. Como una forma de hacer frente a esta situación, se han generado dos instancias institucionales ad hoc para encarar eventuales transformaciones. Se trata de las Comisiones Asesoras Presidenciales (en adelante CAP) de 2006, presidida por el economista Mario Marcel y la del 2015, presidida por el también economista David Bravo. Es posible comprender ambas comisiones como ejemplos de poder y representación tecnocrática (Caramani, 2017), tanto por su conformación y su forma de operar, como por las recomendaciones que emanaron de ellas. Se trató de espacios de trabajo copados por agentes de perfil tecnocrático, en atención a su formación profesional y grado de expertise, que si bien estuvieron en contacto con organizaciones de la sociedad civil mediante diferen-

1 De acuerdo con la Encuesta Plaza Pública No338, aplicada durante la primera semana de julio de 2020 , un $83 \%$ se mostró a favor del retiro excepcional del $10 \%$ de fondos previsionales.

2 Tanto en el Senado como en la Cámara de Diputados la votación a favor del proyecto superó los $2 / 3$, que corresponde al cuórum calificado más alto en la legislación chilena. 
tes canales, monopolizaron las instancias decisorias. Su tratamiento del asunto previsional propició la sustracción de la discusión política democrática de materias sociales y económicas sustantivas (SánchezCuenca, 2020), con una serie de recomendaciones que se alinean con los principios neoliberales y contribuyen a su continuidad, pues ellas toman la forma de ajustes antes que de transformaciones.

De esta forma, el estudio de ambas CAP, como ejemplo de poder y representación tecnocrática para el tratamiento de asuntos económicos dentro del sistema neoliberal, encarna una instancia provechosa, justamente, para comprender el tipo de relación que media entre el neoliberalismo y la tecnocracia en Chile. Se arguye que, como vínculos preponderantes entre ambos regímenes de poder, se encuentra el convencimiento respecto de la conveniencia de sustraer de la deliberación democrática la discusión acerca de los principios económicos que articulan la sociedad, así como también una concepción compartida de la democracia, a la que se estima favorable solo en la medida que funciona como un mecanismo pacífico de sustitución de autoridades y solución de controversias, con una soberanía reducida, especialmente en asuntos relativos al funcionamiento de la economía.

A continuación, se realiza una breve revisión teórica en torno al concepto de neoliberalismo, para luego avanzar hacia su vínculo con la tecnocracia. Se sostiene que entre ambos media una relación que los fortalece mutuamente, la que a la vez debilita a la democracia. Luego se examina sucintamente la arquitectura económica del neoliberalismo en Chile. El apartado teórico finaliza con una revisión de las principales características de las CAP. El artículo continúa con una caracterización metodológica de la investigación y la presentación de los principales resultados. Se culmina presentando las principales conclusiones.

\section{Teoría}

\section{Neoliberalismo}

El neoliberalismo tiene sus primeros antecedentes en el Coloquio de Lippmann, en agosto de 1938, y su consolidación en la plataforma de la Mont Pèlerin Society a partir de 1947, en donde confluyeron corrientes ordoliberales, austriacas y de Chicago (Mirowski y Plehwe, 2009). 
Puede comprenderse como una respuesta ante la decadencia de las sociedades liberales, configuradas en torno a la acción de individuos independientes que organizan su vida en función de los principios de la libertad y la competencia, por efecto del creciente peso del Estado en los países afectados por la Primera Guerra Mundial y por la crisis económica de 1929, que tuvo como consecuencia la inauguración de los regímenes de Bienestar. Es de esta forma que tales corrientes se instituyen en una reacción que persigue el retorno de la hegemonía liberal, mediante un rescate y renovación de sus principios, para hacer frente a la arremetida keynesiana. Ella propugnaba por un Estado interventor de la economía, que permitiera constituir sus bases, y que no actuara meramente como un asegurador de su despliegue, como sería entendido a partir de ese entonces por el proyecto neoliberal. Esta articulación se logra capturar cabalmente cuando se le comprende como un proyecto social que busca trascender su esfera originaria, la economía, hacia el sistema político, consolidando sus pretensiones universalistas (Brown, 2015; Laval y Dardot, 2013). El humano, dentro de él, es caracterizado como un sujeto que actúa acorde con la racionalidad económica y su autointerés, en gran parte de su trayectoria vital (Foucault, 2008).

Es a partir de esta noción fundadora que el rol que asume el Estado corresponde al de asegurador de las condiciones de mercado, en donde los individuos interactúen libremente y coordinados en función del sistema de precios (Friedman, 1962). Este modo particular de coordinación es expandido mediante la privatización de la vida social, la financiarización de la economía y la neutralización de la potencia política transformadora (Harvey, 2007; Lazzarato, 2020). De esta forma, el orden mercantil y las relaciones que propicia se presentan como superiores a cualquier otro régimen relacional histórico, tanto por la neutralidad axiomática de la competencia económica, como por su nivel de eficiencia en la distribución de recursos, bienes y servicios, que tienen por corolario la generación de un sistema social ordenado merced a la racionalidad de los agentes que la componen (Buchanan, 1979; Hayek, 1980).

La pretensión universalista neoliberal, por su parte, queda consignada en su interés por expandir las lógicas del mercado hacia otras esferas sociales, por ejemplo, hacia la política. Ella debe guiarse, se ar- 
gumenta, en función de los principios de racionalidad y eficiencia. A consecuencia de ello, la democracia es valorada en tanto mecanismo de sustitución pacífica de los agentes gubernamentales, al tiempo que es conceptualizada como riesgosa respecto de su capacidad transformadora, la que debe ser constreñida mediante una arquitectura institucional que la vuelva estéril en lo relativo a reestructuraciones del funcionamiento de la economía (Davies, 2014).

\section{Neoliberalismo y tecnocracia}

El neoliberalismo corresponde a un conjunto de principios que, pese a las variadas vertientes que lo nutren, las que incluso cobijan controversias entre sí, tienden a converger en función de tres ejes. El primero consiste en la recuperación de la idea de libertad individual, la que toma forma en función de los actos racionales e interesados de los actores en contextos de mercados competitivos, coordinados por el sistema de precios (Hayek, 1960). El segundo eje se erige en torno a la imputada supremacía del mercado sobre el Estado como espacio de articulación y organización social, no solo por su mayor eficiencia en la asignación de bienes y servicios, sino también porque permite el despliegue de la libertad individual y valora la racionalidad competitiva (Friedman, 1962). Con la función de sustentar estos ejes, es que aparece la tercera convergencia en el pensamiento neoliberal, y que constituye la novedad respecto de sus raíces liberales: corresponde al renovado rol asignado al Estado en la construcción y aseguramiento de mercados, además de resguardar el Estado de derecho y los órdenes constitucionales, el derecho de propiedad y el principio de responsabilidad individual (Brown, 2015).

Es esta particular visión de mundo la que actores e instituciones neoliberales buscan imponer sobre el manejo de la sociedad, otorgando primacía a los principios de mercado sobre otros posibles articuladores sociales, que son asegurados por un gobierno limitado que respalda y propicia las condiciones para su despliegue. El vínculo central está determinado por la generación de mercados competitivos, cuyas reglas y modos de funcionamiento aseguren la libertad de los individuos que interactúan allí.

El neoliberalismo, en tanto proyecto político, se afinca en la economía, campo disciplinario que logró colonizar, al punto de devenir en 
corriente principal, pues a partir de su dimensión racional busca explicar procesos y fenómenos sociales desde la perspectiva de la eficiencia y la distribución. Desde su dimensión normativa o moral, y haciendo uso de las depuradas herramientas técnicas con que dispone, apunta a maximizar el bienestar social, el que se comprende en función de la agregación de éxitos de racionalidades individuales (Hayek, 1980). La extendida presencia de principios neoliberales en las corrientes de pensamiento económico más influyentes en la actualidad reduce las tensiones y los desacuerdos generales sobre los medios y fines de las políticas económicas. Esta condición se constituye en una ventaja epistemológica, que no solo robustece su potencial heurístico, sino que también favorece la adopción de un conjunto de políticas públicas coherentes entre sí, consolidando su pretensión universalista al proyectar sus recomendaciones hacia otros campos sociales y disciplinares (Przeworski, 1992).

Ahora bien, ¿qué ocurre cuando el neoliberalismo toma lugar en regímenes democráticos? Se constata la presencia de dinámicas ambivalentes. Por un lado, la relación que media entre el neoliberalismo y la democracia liberal es fluida, pues se valora de esta última la generación de instituciones que favorecen las libertades individuales y limitan el poder del Estado (Schumpeter, 1983). La afinidad electiva se refuerza respecto de su dimensión procedimental, desde la cual es posible comprender la democracia como un método pacífico para la selección y renovación de las élites de gobiernos, que además goza de legitimidad social por su potencial para la solución de controversias.

No obstante, la valorada libertad de los individuos limita de forma problemática con el neoliberalismo cuando es utilizada para la conformación de proyectos colectivos que tengan el propósito reducir la autonomía de los mercados o minar la soberanía de la economía, relevando de este modo a la política. Es así como se abre un espacio de tensión en lo relativo a la dimensión sustantiva de la democracia, en donde el poder del pueblo es transformador. Ello, pues la democracia se afinca en la noción de autogobierno, mientras que la tecnocracia se sostiene mediante un grupo de agentes de alta influencia política que no son electos democráticamente, ni tampoco rinden cuentas a la población. Esta polémica toma forma, en particular, en el convencimiento neoliberal sobre la necesidad de aislar los principios económicos 
de la discusión democrática y de cualquier potencia sociopolítica que pueda alterar ese orden (Sánchez-Cuenca, 2020). Esto se sustenta en la extendida noción de que la economía es una esfera social que debe ser dominada por la racionalidad técnica, y no por la voluntad general que logra articular la democracia.

Este anotado punto de controversia con la democracia es también el espacio de encuentro con la racionalidad tecnocrática. Al igual que el neoliberalismo, la tecnocracia busca restringir la participación ciudadana en función de las credenciales de saber experto, las que representan requisitos de entrada a las discusiones de resonancia social (Centeno, 1997). Esta restricción impuesta a la participación en la deliberación por parte de la tecnocracia, fundada en la exigencia de expertise como condición de participación política y técnica, reduce los márgenes de la democracia sustantiva, la que en contra de la elitización tecnocrática, apunta a un autogobierno expansivo, con amplia representatividad y capacidad transformadora. Tal operación de reducción democrática en nombre de la razón tecnocrática en contextos neoliberales no deviene en una contracción del poder per se, sino que más bien lo que acontece es un desplazamiento de hegemonía desde el orden democrático y su sustrato popular hacia la esfera del saber técnico y al mercado, en donde la lógica de la igualdad democrática no tiene espacio, en atención a que se imponen dinámicas de concentración y captura del poder por parte de un grupo reducido de agentes de saber especializado acreditado y de actores de gran poder económico.

En esta nueva diagramación del poder, en donde sus vectores son el saber experto y la acumulación financiera, se produce una alquimia entre los principios neoliberales y tecnocráticos respecto de la conveniencia de sustraer las determinaciones de orden económico de la refriega política democrática. La democracia neoliberal, en consecuencia, deviene en una democracia plana (Fishman, 2016), sin componentes sustantivos, limitada a expresiones liberales procedimentales. En ella, las condiciones del funcionamiento de la economía no caen bajo su escrutinio, sino que se encuentran secuestradas por el saber experto tecnocrático, el cual tiende hacia la homogeneidad y actúa en favor del statu quo del libre mercado, y por lo tanto, cuenta con baja capacidad transformadora y escaso potencial representativo (Dargent, 2015). 
En suma, la confluencia entre el neoliberalismo y la tecnocracia tiene como consecuencia, en contextos democráticos, una economía aislada de la política, secuestrada en nombre del saber experto y la continuidad neoliberal. En términos concretos, estos principios toman forma política no solo mediante su constitucionalización (Laval y Dardot, 2013), hecho comprobable en el caso chileno (Ramírez, 2020), sino que también en la delegación de la formación de políticas públicas en cuerpos independientes con alto saber especializado, no electos democráticamente pero, en ocasiones, con mayor influencia que los representantes democráticos, como lo pueden ser los Bancos Centrales y organismos económicos internacionales, donde destacan el Fondo Monetario Internacional y el Banco Mundial. Es también el caso, precisamente, de las CAP, a partir de cuyas recomendaciones se legisla.

Los argumentos neoliberales en favor de la tecnocracia se sustentan en que la última, por un lado, dispone de medios eficientes para asegurar el funcionamiento del mercado, al tiempo que por otro su lógica elitaria morigera el alcance transformador de la democracia. La forma de poder tecnocrática, tanto por su sesgo en favor del mercado como por su restricción elitaria de la democracia, toma forma en las CAP, a través de su preferencia sistemática por mecanismos de mercado y en su conformación censitaria por parte de agentes de saber experto. Adicionalmente, dentro de regímenes democráticos, la tecnocracia es justificada por el discurso neoliberal en función de que los tecnócratas:

- poseen horizontes temporales más amplios que los políticos en busca de reelección;

- no son objeto de presiones políticas ni intereses personales;

- saben más y disponen de mejores herramientas analíticas que políticos profesionales y ciudadanos;

- toman decisiones apoyados en el método científico y en base a evidencia positiva y, en consecuencia;

- alcanzan una mayor calidad deliberativa (Sánchez-Cuenca, 2020).

\section{Neoliberalismo en Chile}

En consideración de los principios neoliberales esbozados, ¿qué efectos produjo su instauración en la arena económica en Chile? Origina- 
da durante la dictadura militar, y a cargo del cuerpo tecnocrático conformado por los Chicago Boys, la implantación del neoliberalismo en Chile tomó forma mediante cuatro transformaciones económicas clave. La primera de ellas consiste en la reforma comercial, que implicó la eliminación de barreras no arancelarias para el comercio internacional y la reducción de tarifas aduaneras (Stallings, 2001). Esta drástica apertura unilateral hacia el exterior, acometida sobre la base de convencimiento de la necesidad de insertar al país en el circuito internacional del comercio, resultó ser uno de los factores que, a la postre, detonaron la dramática crisis económica que propició el neoliberalismo chileno a partir de 1982.

La segunda reforma fue la liberalización financiera interna, con la cual la banca se privatizó e internacionalizó, lo que provocó un aumento en la flexibilidad crediticia y una disminución de los intereses asociados (Gárate, 2012). Es decir, y siguiendo los principios neoliberales, se buscó un flujo financiero sujeto a regulaciones mínimas por parte del Estado, consolidando su liberalización. Esta transformación va en línea con la apertura de la cuenta de capitales, o liberalización financiera internacional, que como tercer elemento reformista, permitió a instituciones extranjeras ingresar capitales a la economía doméstica sin mayores controles estatales (Ffrench-Davis, 2018). A los bancos se les posibilitó tomar préstamos internacionales para financiar sus actividades locales, operación que hacia 1982 derivó en un cuadro extendido de insolvencia bancaria, que conminó al Estado a ejecutar una operación de salvataje por la deuda subordinada.

Por último, tuvo lugar la privatización de las empresas del Estado. En un primer momento, se devolvieron las empresas estatizadas por los anteriores gobiernos, para luego avanzar hacia la cesión a la administración privada de empresas estratégicas del rubro industrial, financiero y comercial (Biglaiser y Brown, 2003; Huneeus, 2016). Es a partir de este proceso que las reformas sociales de inspiración neoliberal toman forma. $\mathrm{Y}$ es que en dictadura, aquello que otrora era entregado bajo la lógica de derechos sociales por parte del Estado, pasó a ser un servicio provisto por el mercado, según sus lógicas de asignación, con los principios de competencia y lucro articulándolos.

Dentro de estas reformas socioeconómicas, se inscribe el Plan Laboral de 1979, cuyo principal objetivo era flexibilizar el mercado del 
trabajo. Para ello, se entregaron ventajosas atribuciones a los empleadores, al tiempo que el poder sindical fue desarticulado (Mizala y Romaguera, 2001). El sistema de salud también fue reformado mediante la introducción de empresas privadas que funcionan cual aseguradoras, configurando un sistema híbrido en conjunto con las responsabilidades del Estado, el que además de seguir proveyendo este servicio público, asegura las condiciones para la generación y funcionamiento de un mercado, en donde los ciudadanos son tratados como usuarios y los derechos como prestaciones (Huneeus, 2014).

La reforma educacional también se encuentra animada por los principios neoliberales que apuntan a introducir mercados dentro de lo que históricamente había funcionado como derecho social. Así, además de debilitar la educación pública mediante el traspaso de la responsabilidad del Estado hacia los municipios, se levantó en paralelo un sistema educacional cuya operación estaba a cargo de privados, desde el nivel preescolar hasta el universitario, quienes podían lucrar con sus prestaciones (Bellei, 2015). Junto a ella, la reforma previsional para la sociedad civil, iniciada con la promulgación del D.L. 3500 el 4 de noviembre de 1980, significó una ruptura con el esquema anterior de fundamentos solidarios, los que fueron considerados económicamente inviables y constituían un profundo engaño político, susceptible de una nociva politización en un tema que debía ser manejado técnicamente (Piñera, 1991). A cambio, fueron reemplazados por un sistema de capitalización individual con su gestión a cargo de entidades privadas de giro único, las Administradoras de Fondos de Pensiones (AFP), a las que desde mayo de 1981 se les permitió lucrar con esta prestación social (Uthoff, 2001).

Cada una de estas reformas en particular apuntó a favorecer la competencia entre empresas privadas en los nuevos mercados creados por parte del Estado, transformando su historia previa de concepción de los individuos como ciudadanos titulares de derechos sociales hacia una en donde son tratados como consumidores de servicios sociales neoliberales (Atria, 2013). En su conjunto, las sucesivas políticas de inspiración neoliberal apuntan a una nueva modelación social, en donde, como ya ha sido anotado, se tiende a favorecer la competencia en el mercado antes que la cooperación coordinada por el Estado, proceso que sienta las bases para la consolidación de la acumulación 
capitalista (Harvey, 2007). Esta dinámica tiene al Estado de garante, al traspasar sus otrora funciones sociales hacia grandes grupos económicos que asumen funciones sociales desde la lógica de la competencia y el lucro mediante su despliegue en el mercado. Siguiendo a Hall (1993), lo que aconteció en Chile fue un cambio de paradigma económico, y también político, en donde la organización desarrollista, con un Estado empresario a la cabeza, fue reemplazada por un esquema de neoliberalismo ortodoxo.

Adicionalmente, con la polarización política que precedió al Golpe de Estado, junto con la clausura autoritaria del Congreso y la prohibición de los partidos políticos, se abrió espacio para el surgimiento de una nueva clase de actores profesionales. Ellos transitaron desde la sociedad civil hacia el Estado, y se encargaron de la formulación de políticas públicas desde una perspectiva que, por un lado, apoyados en la razón científica, los alejara de la polarización ideológica precedente y, por otro, los liberara del condicionamiento de los otrora funcionarios de gobierno y miembros activos de partidos políticos (Silva, 2012). Este movimiento doblemente fundado puede comprenderse como prolegómeno del futuro auge de las CAP, a modo de instancia prelegislativa de elaboración de políticas públicas, en donde, lejos de la refriega democrática, y amparados en el consenso tecnocrático, se alcanzan preacuerdos de índole técnica que allanan la tramitación de proyectos de ley.

\section{Comisiones Asesoras Presidenciales, CAP}

Históricamente, el neoliberalismo se ha servido de una concepción política tecnocrática, pues ha apostado por la resolución de los problemas dentro de un contexto técnico-económico, en donde sus cultores se sienten mucho más cómodos. Es ahí en donde sus conocimientos especializados y lenguaje técnico encuentran un campo fértil para su desarrollo, alejados de la esfera política, en donde las posiciones tienden a la polarización y sus habilidades son débiles (Joignant, 2012). Esta figura ha consumado un consenso elitario en torno a la despolitización del Estado y su gestión económica, apostando por una relativa autonomización del funcionamiento del mercado, pues un objetivo explícito del neoliberalismo ha sido la despolitización de la economía, mientras que el implícito es la despolitización de la sociedad (Lechner, 
1998). Sobre la base de estos principios, la exacerbación de los conflictos sociales es considerada una fuente de inestabilidad política e ineficiencia productiva (Hayek, 1980; Huntington, 1972), ante los cuales el neoliberalismo tramita capturando las discusiones, condicionando su acceso a ellas gracias a la acreditación de conocimiento especializado. Esta despolitización consolida el dominio del conocimiento experto, el que ha empujado a la integración de las lógicas de funcionamiento del mercado por parte del Estado (Joignant y Güell, 2011).

Este proceso es concomitante respecto de la modernización y creciente complejidad del sistema político y económico. Se trató, con el auge del neoliberalismo y de variantes neoestructuralistas, del fin del modelo desarrollista y del Estado de compromiso, buscando ingresar al modelo competitivo del comercio internacional globalizado. Ello fortaleció la posición de los tecnócratas en las cúpulas de gobierno (Silva, 2012), especialmente con el auge de la Nueva Administración Pública y la resonancia del Consenso de Washington (1989) que entregó a los tecnócratas y, particularmente a los economistas, roles preponderantes en el aparato gubernamental, tales como los Ministerios de Hacienda y Economía, junto con Bancos Centrales, organismos de planificación y también comisiones asesoras.

Sin embargo, las sucesivas experiencias democratizadoras imprimieron nuevas exigencias ciudadanas hacia los líderes políticos, especialmente por mayor incidencia en la toma de decisiones (Sousa Santos, 2004), aunque también por un mayor conocimiento y dominio de saberes especializados por parte de los políticos en el ejercicio de su poder. Esta demanda fue atendida parcialmente por los nuevos demócratas, quienes generaron innovadoras instancias de participación. Dentro de estas iniciativas se enmarcan, en el caso de Chile, las CAP, con amplia presencia internacional en las democracias desarrolladas (Zegart, 2004), las que representan un mecanismo de participación civil restringida, fruto de la tensión entre la demanda democrática y la representación política tecnocrática en contextos de alta incidencia neoliberal.

Sus orígenes, en general, pueden responder tanto a una forma de contención del debate inaugurado por movimientos sociales, como a un nuevo mecanismo para encarar la crisis de participación democrática (Delamaza, 2010). También reconoce un sostenido debilitamiento 
de los partidos políticos en cuanto a su capacidad de identificar y canalizar las demandas sociales para el mejoramiento de políticas públicas, rol asumido por un ascendente cuerpo independiente de agentes de saber especializado (Silva, 2010).

Una de las principales características de este tipo de comisiones -utilizada por todos los gobiernos chilenos desde la recuperación democrática en 1990-, consiste en que son dominadas por agentes técnicos de saber especializado, lo que implica una amplitud ideológica limitada (Aguilera, 2009). Adicionalmente, no suelen contar con una proyección temporal que traspase el proceso de formulación de propuestas hacia la discusión legislativa y la implementación (Osorio, 2018). En consecuencia, pese a que estas instancias permiten la manifestación de diversas posturas y propician el diálogo entre ellas, su alcance es restringido por el carácter técnico que lo anima y por las trayectorias políticas con que suelen contar sus participantes, además de las asimetrías de poder entre los afectados por las políticas públicas respecto del cuerpo tecnocrático (Mascareño, 2010). No obstante, la virtud política con que cuentan, valorada ampliamente por los gobiernos, consiste en que el prestigio de sus agentes independientes, fundado en su expertise, cuando toma forma de recomendaciones concretas recogidas para la posterior legislación, puede ser traspasada hacia la clase política. Tiene lugar, en consecuencia, una dinámica de doble ganancia: mientras el gobierno ve cómo sus propuestas adquieren mayor aceptación ciudadana, los tecnócratas logran mayor ascendencia en el sistema político (Zegart, 2004).

En términos generales, los comisionados presentan trayectorias profesionales en donde prevalece el alto saber experto, aunque también se encuentran actores que cuentan con experiencia en asuntos de gobierno y, en menor medida, representantes de grupos de interés (Aguilera y Fuentes, 2011). Ellos poseen dos tipos de capitales, que sirven de fuente de legitimación: el cultural, que deriva de su formación especializada en economía y políticas públicas; y el social, asociado a su historial como asesores y consultores dentro del sistema político. Es de esta forma que en las CAP se constata la formación de una nueve elite de expertos, ya no formados tradicionalmente en leyes, sino que crecientemente en economía e ingeniería. Esta nueva intelligentsia, en su mayoría, no es miembro de partidos políticos, pues prefieren la in- 
dependencia o el vínculo directo con think tanks, en atención a que valoran su autonomía intelectual y relevan su pericia técnica al tomar decisiones, antes que responder políticamente a las determinaciones partidarias. De esta forma, su rol también puede entenderse a modo de articulación entre el saber experto, vinculado al mundo intelectual y la academia, y la actividad política profesional (Weber, 2012).

Las CAP se originan por mandato presidencial, con miembros designados según su discrecionalidad, y buscan representar el equilibrio político del momento mediante la inclusión de agentes distintivos de las principales fuerzas del escenario político. Esto condiciona su amplitud ideológica y técnica, en línea con su pretensión de introducir objetividad en el trabajo previo de proyectos de ley. También contribuye a la fortaleza presidencial en el proceso legislativo (Toro, 2007). Cabe destacar que no son instituciones formales reconocidas por la legislación chilena, por lo que no se encuentran reguladas en su origen, composición o funcionamiento, lo que genera una gran flexibilidad en su conformación. Su forma de trabajo se encuentra orientada por la lógica consensual, pues su labor debe consagrarse en un cuerpo de recomendaciones respaldadas por la mayoría de la comisión, aunque con espacio para la consignación de divergencias. Este sesgo en favor de los acuerdos restringe su alcance transformador y orienta las recomendaciones hacia ajustes, favoreciendo posiciones cercanas al statu quo.

Así, resulta posible comprender estas instancias como una forma de espacios de fomento y reproducción de la representación tecnocrática neoliberal, tomando en cuenta su composición censitaria, su escaza politización, y la captura deliberativa de temas de alta resonancia social, en dinámicas de trabajo en donde prima el perfil experto antes que la representación plural ciudadana. Este fenómeno abre un espacio para la representación política tecnocrática, la que tiene cuatro características principales. En primer lugar, la convicción de que existe un bien común objetivo para las sociedades, el cual es conocible mediante el método científico y alcanzable a través de la acción racional coordinada (Centeno, 1997). En segundo lugar, una visión no pluralista de la sociedad, lo que permite comprenderla como un todo. Esto se entronca, a su vez, con la tercera característica, según la cual la intermediación política no tiene lugar, porque los intereses individuales se 
subsumen, mediante agregación, en el interés general. Por último, se destaca que los tecnócratas no tienen entre sus preocupaciones - a diferencia de políticos democráticos-, la necesidad de rendir cuentas ante la ciudadanía (Caramani, 2017).

Estos nuevos expertos, en consecuencia, no actúan meramente en el plano técnico, pues sus informes contienen un profundo sentido político, especialmente cuando asumen dinámicas prelegislativas y sus recomendaciones se concretizan en políticas públicas. Inauguran, de este modo, un nuevo tipo de agente social, el que pese a no ser electo democráticamente, logra alta ascendencia política, ya que para ellos no son los votos su fuente de legitimidad, sino que sus credenciales académicas. En términos más generales, Brown (2009) señala que el saber científico es susceptible de politizarse cuando se desenvuelve en instituciones que cobijan poder y conflicto. Esta situación entra en tensión con los principios democráticos sustantivos, no así necesariamente con aquellos que fundamentan la democracia liberal, sobre la cual se sustenta el auge del poder tecnocrático.

\section{Metodología}

Este trabajo, convencido del carácter acumulativo del conocimiento (Geddes, 2003), busca aportar a la creciente literatura referida a la resiliencia neoliberal, como fenómeno mundial, con Chile como ejemplo destacado. Con tal propósito, observa la continuidad del singular esquema de pensiones chileno como caso de estudio, el que no solo fue desarrollado e implementado en la fase cénit del neoliberalismo autoritario (Ffrench-Davis, 2018), sino que también se funda en principios neoliberales, como la privatización del sistema, su mercantilización y el dominio de la competencia sobre la solidaridad, con un Estado que asume un rol subsidiario. Estas características, adicionalmente, han mantenido su vigencia, pese a la transición política de 1990 y la consolidación democrática, con cinco gobiernos auto declarados de centroizquierda.

Para comprender la resiliencia que ha exhibido el sistema de pensiones, se intenta entender el impacto del tratamiento tecnocrático del que ha sido objeto el esquema previsional por parte de dos instancias reformadoras, las CAP ad hoc de 2006 y 2015 . Se postula, a modo de hipótesis de trabajo, que la composición tecnocrática de ambas comisio- 
nes representa un espectro limitado de posiciones políticas y técnicas, condición que refuerza la probabilidad de mantención del sistema de pensiones, en atención a que las alternativas a los principios neoliberales carecen de influencia sustantiva. En términos más generales, de esta situación se desprende que el saber tecnocrático es utilizado por el neoliberalismo como un espacio de consolidación y proyección, pues existen puntos de encuentro entre ambos regímenes de poder, siendo el más resonante la concordancia en sustraer el debate económico de la discusión democrática.

En línea con desarrollos metodológicos recientes de las ciencias sociales, esta investigación buscó realizar el trabajo de inferencia causal dentro de su caso de estudio en profundidad y no necesariamente a nivel comparado (Collier, 2011). De este modo, y como objetivo general, se investigó la composición y el trabajo de las CAP sobre el sistema de pensiones de 2006 y 2015, con el propósito de distinguir, como objetivos específicos, criterios de nominación de sus integrantes, además del alcance transformador de sus propuestas. El acceso a los datos es abierto, y se encuentran contenidos principalmente en los Informes finales de ambas comisiones.

\section{Resultados}

\section{CAP para la reforma previsional de 2006}

En respuesta a las críticas por la baja cuantía de las pensiones entregadas por las AFP, y en cumplimiento de una de sus promesas de campaña, la expresidenta Michelle Bachelet convocó durante la primera semana de su mandato al Consejo Asesor Presidencial para la reforma previsional, también llamada Comisión Marcel. Su creación, que también apuntaba a ajustar el paquete de reformas esbozado en el programa de gobierno, se oficializó mediante la promulgación del Decreto N³36 del 17 de marzo del 2006. Reunió a quince profesionales encargados de "elaborar propuestas para reformar el sistema de pensiones (...). Dichas propuestas estarán orientadas a resolver los principales problemas del sistema vigente e identificar otras medidas complementarias". Su presidente fue el economista Mario Marcel, cercano al Partido Socialista, miembro del centro de estudios CIEPLAN y presidente del Banco Central para el período entre 2016 y 2021. 
Al revisar la trayectoria académica de sus integrantes, contenida en la Tabla 1, destaca que el $93 \%$ de los comisionados haya estudiado su pregrado en la Universidad de Chile o en la Pontificia Universidad Católica de Chile. Esta alta cohesión tiene lugar en uno de los más importantes espacios de socialización, con fuertes vínculos intra y extracomunitarios (Cisternas y Vásquez, 2018), desde los cuales comienza a tomar forma su trayectoria profesional. Este fenómeno se proyecta también en su formación original, pues un $67 \%$ de los comisionados estudió Economía a nivel de pregrado. La homogeneidad del grupo se consolida en función de su entrenamiento de posgrado, con un $87 \%$ de los integrantes con instrucción a nivel de máster o de doctorado, y un 67\% con especialización en Economía. La influencia del mainstream económico está dada cuando se constata que un 53\% de los miembros de la Comisión Marcel tiene un posgrado en Economía en alguna universidad estadounidense de prestigio.

Tabla 1

Formación académica de integrantes de Comisión Marcel (2006)

\begin{tabular}{|c|c|c|}
\hline Integrante & Grado académico & $\begin{array}{l}\text { Máximo grado } \\
\text { académico }\end{array}$ \\
\hline 1. Mario Marcel & $\begin{array}{l}\text { Ingeniería comercial* } \\
\text { (Universidad de Chile) }\end{array}$ & $\begin{array}{l}\text { Máster en Economía } \\
\text { (Universidad de } \\
\text { Cambridge) }\end{array}$ \\
\hline 2. Harald Beyer & $\begin{array}{l}\text { Ingeniería comercial } \\
\text { (Universidad de Chile) }\end{array}$ & $\begin{array}{l}\text { PhD. En Economía } \\
\text { (Universidad de } \\
\text { California) }\end{array}$ \\
\hline 3. David Bravo & $\begin{array}{l}\text { Ingeniería comercial } \\
\text { (Pontificia Universidad } \\
\text { Católica de Chile) }\end{array}$ & $\begin{array}{l}\text { Máster en Economía } \\
\text { (Universidad de } \\
\text { Harvard) }\end{array}$ \\
\hline 4. Axel Christensen & $\begin{array}{l}\text { Ingeniería civil } \\
\text { industrial (Pontificia } \\
\text { Universidad Católica de } \\
\text { Chile) }\end{array}$ & $\begin{array}{l}\text { Máster en Economía } \\
\text { (Universidad de } \\
\text { Stanford) }\end{array}$ \\
\hline 5. Regina Clark & $\begin{array}{l}\text { Derecho (Pontificia } \\
\text { Universidad Católica de } \\
\text { Chile) }\end{array}$ & $\begin{array}{l}\text { Derecho (Pontificia } \\
\text { Universidad Católica de } \\
\text { Chile) }\end{array}$ \\
\hline 6. Álvaro Clarke & $\begin{array}{l}\text { Ingeniería comercial } \\
\text { (Universidad de Chile) }\end{array}$ & $\begin{array}{l}\text { Máster en Economía } \\
\text { (Universidad de } \\
\text { Lovaina) }\end{array}$ \\
\hline
\end{tabular}




\begin{tabular}{lll}
\hline 7. Rossana Costa & $\begin{array}{l}\text { Ingeniería comercial } \\
\text { (Pontificia Universidad } \\
\text { Católica de Chile) }\end{array}$ & $\begin{array}{l}\text { Ingeniería comercial } \\
\text { (Pontificia Universidad } \\
\text { Católica de Chile) }\end{array}$ \\
\hline 8. Martín Costabal & $\begin{array}{l}\text { Ingeniería comercial } \\
\text { (Pontificia Universidad } \\
\text { Católica de Chile) }\end{array}$ & $\begin{array}{l}\text { Máster en Economía } \\
\text { (Universidad de } \\
\text { Chicago) }\end{array}$ \\
\hline 9. Margarita Errázuriz & $\begin{array}{l}\text { Sociología (Pontificia } \\
\text { Universidad Católica de } \\
\text { Chile) }\end{array}$ & $\begin{array}{l}\text { Sociología (Pontificia } \\
\text { Universidad Católica de } \\
\text { Chile) }\end{array}$ \\
\hline 10. Alejandro Ferreiro & $\begin{array}{l}\text { Derecho (Universidad } \\
\text { de Chile) }\end{array}$ & $\begin{array}{l}\text { Máster en Derecho } \\
\text { (Universidad de Notre }\end{array}$ \\
\hline 11. Augusto Iglesias & $\begin{array}{l}\text { Ingeniería comercial } \\
\text { (Pontificia Universidad } \\
\text { Católica de Chile) }\end{array}$ & $\begin{array}{l}\text { Máster en Economía } \\
\text { (Universidad de } \\
\text { California) }\end{array}$ \\
\hline 12. Alejandra Mizala & $\begin{array}{l}\text { Ingeniería comercial } \\
\text { (Universidad de Chile) }\end{array}$ & $\begin{array}{l}\text { PhD en Economía } \\
\text { (Universidad de }\end{array}$ \\
& Berkeley) \\
\hline 13. Andrea Repetto & $\begin{array}{l}\text { Ingeniería comercial } \\
\text { (Pontificia Universidad } \\
\text { Católica de Chile) }\end{array}$ & $\begin{array}{l}\text { PhD en Economía } \\
\text { (Instituto de Tecnología } \\
\text { de Massachusetts) }\end{array}$ \\
\hline 15. Andras Uthoff & $\begin{array}{l}\text { Ingeniería comercial } \\
\text { (Universidad de Chile) }\end{array}$ & $\begin{array}{l}\text { PhD. En Economía } \\
\text { (Universidad de } \\
\text { Berkeley) }\end{array}$ \\
& Sociología (Universidad \\
& $\begin{array}{l}\text { PhD. En Sociología } \\
\text { (Universidad de }\end{array}$ \\
& Lovaina) \\
\hline
\end{tabular}

*En Chile, a nivel de pregrado, se homologa la carrera de Ingeniería Comercial a la de Economía.

Fuente: Elaboración propia sobre la base del informe El derecho a una vida digna en la vejez. Hacia un contrato social con la previsión en Chile (CAP, 2006).

Desde la sociedad civil surgieron voces críticas respecto de la composición de la comisión. La Central Unitaria de Trabajadores (CUT) y miembros de movimientos de izquierda sin representación en el Congreso, argumentaron que entre los integrantes no se encontraban personeros abiertamente críticos del sistema. Por su parte, las agrupaciones de afiliados a las AFP, señalaron que "tan solo con saber quiénes serían los consejeros se podía apreciar la falta de pluralidad con que se abordaría el problema de la reforma previsional y el carácter puramente técnico que adquiriría su discusión" (Garretón et al., 2012, pp. 311-312). 
Su trabajo contempló, en primera instancia, y en búsqueda de mayor legitimidad social, un ciclo de un mes de audiencias con distintas entidades de la sociedad civil. Esto va en línea con la recomendación de vincular el conocimiento experto con la participación ciudadana en la formulación de políticas públicas (Fisher, 2009). Posteriormente, su labor consistió en la evaluación de variados informes académicos previsionales, además de la sistematización de la información recabada en las audiencias. En términos generales, se concluyó que si bien el esquema funcionaba en línea con lo proyectado, el crecimiento y la evolución demográfica por sobre lo esperado introdujo nuevas exigencias que no pudieron ser del todo cumplidas por el régimen. Entre ellas se encontraban el aumento de la esperanza de vida, una decreciente capacidad del mercado laboral para incorporar a nuevos trabajadores, y una creciente participación de mujeres en el trabajo. A partir de este diagnóstico, se formaron dos grupos de trabajo, cada uno de ellos dedicado a un análisis en profundidad de dos de los ejes en los que se centraría el Consejo: la creación de un fondo con cargo a rentas generales para el complemento previsional y temas diversos relativos al funcionamiento del mercado de pensiones.

El informe final presentó un paquete de cerca de un centenar de recomendaciones, atingentes a la necesidad de aumentar la cobertura, mejorar la cuantía de las pensiones y fomentar la competencia entre las instituciones previsionales. Entre ellas, destacan la introducción de un mecanismo solidario para el fortalecimiento de las pensiones más bajas, bonificación por hijo a las mujeres, equidad de género en el seguro de invalidez y sobrevivencia, subsidio previsional a trabajadores jóvenes de bajos ingresos, licitación de nuevos cotizantes y la incorporación de trabajadores independientes al sistema. La totalidad de las propuestas corresponden a cambios de primer y segundo orden (Hall, 1993), pues si bien se ajustan los instrumentos de política pública y su configuración, la jerarquía de objetivos se mantiene inalterada, sin una ruptura paradigmática con el neoliberalismo.

Entre las medidas propuestas por la Comisión Marcel, solo la creación de un fondo de asistencia solidario atañe el núcleo neoliberal del sistema de pensiones, definido por la administración mercantilizada del sistema previsional y la capitalización individual. Esta recomendación se materializa mediante la promulgación de la Ley $\mathrm{N}^{\circ} 20.255$, la 
cual sustituye la Pensión Mínima por el Aporte Previsional Solidario, conocido comúnmente como Pilar Solidario. Corresponde a un mecanismo de carácter solidario y subsidiario, con cargo a rentas generales, que busca corregir las insuficiencias del esquema de capitalización individual. En un primer momento, el Estado participaba en las pensiones entregadas al 40\% más pobre del país, hasta que en 2012 se expandió hasta alcanzar el $60 \%$ (Castiglioni, 2018). No obstante, en atención a que no se transformó el principio nuclear de capitalización individual, sino que solo se le apuntalaba, esta reforma marca el paso desde un neoliberalismo ortodoxo hacia uno mixto, en atención a la mayor participación del Estado (Maillet, 2015). Es de esta forma en que el neoliberalismo asegura su continuidad: introduciendo ajustes al sistema antes que transformaciones que alteren sus principios.

\section{CAP para reforma previsional de 2015}

La CAP sobre el sistema de pensiones convocada por la presidenta Michelle Bachelet, trabajó entre abril del 2014 y septiembre del 2015 y estuvo compuesta por 24 integrantes. Según el Decreto Presidencial $\mathrm{N}^{\circ} 718$ de 2014, su objetivo era "estudiar el Sistema de Pensiones, realizar un diagnóstico acerca del actual funcionamiento de estos cuerpos normativos y elaborar propuestas destinadas a resolver las deficiencias que se identifiquen". Bajo la presidencia del economista David Bravo, realizó un análisis crítico del sistema previsional privado, identificando importantes temas por resolver, entre los que se encuentran las bajas asignaciones pagadas, las grandes lagunas en las cotizaciones y las desigualdades de género.

A partir de su diagnóstico existieron tres grandes propuestas excluyentes entre sí: la primera planteaba ajustes en busca de un fortalecimiento del actual sistema de capitalización individual y alcanzó 12 votos. La segunda buscaba complementar el sistema con componentes solidarios y tuvo 11 votos. La tercera apostaba por una transformación estructural hacia un sistema de reparto y logró 1 voto. Su informe final considera 58 propuestas articuladas en 11 áreas temáticas, aunque sin un consenso amplio respecto de las recomendaciones formuladas (CAP, 2015).

Un análisis de las trayectorias académicas de sus 24 comisionados, sintetizada en la Tabla 2, muestra que el $62 \%$ de ellos realizó sus estu- 
dios de pregrado en la Universidad de Chile o en la Pontificia Universidad Católica de Chile, las dos más influyentes del país. La reducción en este ámbito en relación con la proporción de la Comisión Marcel (2005) responde a que ocho integrantes eran extranjeros, pues entre los nacionales, un $94 \%$ se graduó de una de las dos universidades. La comisión estuvo dominada por economistas, tanto a nivel de pregrado (67\%), como de posgrado (71\%), con la mitad de los integrantes con estudios de posgrado en Economía en alguna universidad de prestigio de Estados Unidos. Si en la comisión antecesora el 87\% de sus miembros contaba con estudios a nivel de magíster o doctorado, en el grupo convocado el 2015 la totalidad de sus integrantes disponen de estas credenciales.

Tabla 2

Formación académica de integrantes de Comisión Bravo (2015)

\begin{tabular}{|c|c|c|}
\hline Integrante & Grado académico & Máximo grado académico \\
\hline 1. David Bravo** & $\begin{array}{l}\text { Ingeniería comercial* } \\
\text { (Pontificia Universidad } \\
\text { Católica de Chile) }\end{array}$ & $\begin{array}{l}\text { Máster en Economía } \\
\text { (Universidad de Harvard) }\end{array}$ \\
\hline 2. Cecilia Albala & $\begin{array}{l}\text { Medicina (Pontificia } \\
\text { Universidad Católica de } \\
\text { Chile) }\end{array}$ & $\begin{array}{l}\text { Máster en Medicina } \\
\text { (Universidad de Chile) }\end{array}$ \\
\hline 3. Orazio Attanasio & $\begin{array}{l}\text { Economía (Universidad de } \\
\text { Bolonia) }\end{array}$ & $\begin{array}{l}\text { PhD. En Economía (Escuela } \\
\text { de Economía y Ciencia } \\
\text { Política de Londres) }\end{array}$ \\
\hline 4. Nicholas Barr & $\begin{array}{l}\text { Economía (Escuela de } \\
\text { Economía y Ciencia Política } \\
\text { de Londres) }\end{array}$ & $\begin{array}{l}\text { PhD. En Economía } \\
\text { (Universidad de Berkeley) }\end{array}$ \\
\hline 5. Fabio Bertranou & $\begin{array}{l}\text { Economía (Universidad } \\
\text { Nacional de Cuyo) }\end{array}$ & $\begin{array}{l}\text { PhD. En Economía } \\
\text { (Universidad de Pittsburgh) }\end{array}$ \\
\hline 6. Hugo Cifuentes & $\begin{array}{l}\text { Derecho (Universidad de } \\
\text { Chile) }\end{array}$ & $\begin{array}{l}\text { Doctor en Derecho } \\
\text { (Universidad Complutense } \\
\text { de Madrid) }\end{array}$ \\
\hline 7. Regina Clark** & $\begin{array}{l}\text { Derecho (Pontificia } \\
\text { Universidad Católica de } \\
\text { Chile) }\end{array}$ & $\begin{array}{l}\text { Derecho (Pontificia } \\
\text { Universidad Católica de } \\
\text { Chile) }\end{array}$ \\
\hline 8. Martín Costabal** & $\begin{array}{l}\text { Ingeniería comercial } \\
\text { (Pontificia Universidad } \\
\text { Católica de Chile) }\end{array}$ & $\begin{array}{l}\text { Máster en Economía } \\
\text { (Universidad de Chicago) }\end{array}$ \\
\hline 9. Carlos Díaz & $\begin{array}{l}\text { Ingeniería comercial } \\
\text { (Pontificia Universidad } \\
\text { Católica de Chile) }\end{array}$ & $\begin{array}{l}\text { Máster en Economía } \\
\text { (Universidad de California) }\end{array}$ \\
\hline 10. Christian Larraín & $\begin{array}{l}\text { Ingeniería comercial } \\
\text { (Universidad de Chile) }\end{array}$ & $\begin{array}{l}\text { Máster en Economía } \\
\text { (Universidad de Lovaina) }\end{array}$ \\
\hline
\end{tabular}




\begin{tabular}{|c|c|c|}
\hline 11. Costas Meghir & $\begin{array}{l}\text { Economía (Universidad de } \\
\text { Manchester) }\end{array}$ & $\begin{array}{l}\text { PhD. En Economía } \\
\text { (Universidad de } \\
\text { Manchester) }\end{array}$ \\
\hline $\begin{array}{l}\text { 12. Carmelo Mesa- } \\
\text { Lago }\end{array}$ & $\begin{array}{l}\text { Derecho (Universidad de La } \\
\text { Habana) }\end{array}$ & $\begin{array}{l}\text { PhD. En Economía } \\
\text { (Universidad de Cornell) }\end{array}$ \\
\hline 13. Olivia Mitchell & $\begin{array}{l}\text { Economía (Universidad de } \\
\text { Harvard) }\end{array}$ & $\begin{array}{l}\text { PhD. En Economía } \\
\text { (Universidad de Wisconsin- } \\
\text { Madison) }\end{array}$ \\
\hline $\begin{array}{l}\text { 14. Verónica } \\
\text { Montecinos }\end{array}$ & $\begin{array}{l}\text { Sociología (Pontificia } \\
\text { Universidad Católica de } \\
\text { Chile) }\end{array}$ & $\begin{array}{l}\text { PhD. En Sociología } \\
\text { (Universidad de Pittsburgh) }\end{array}$ \\
\hline 15. Leokadia Oreziak & $\begin{array}{l}\text { Economía (Universidad de } \\
\text { Varsovia) }\end{array}$ & $\begin{array}{l}\text { PhD. En Economía } \\
\text { (Universidad de Varsovia) }\end{array}$ \\
\hline 16. Joakim Palme & $\begin{array}{l}\text { Sociología (Universidad de } \\
\text { Estocolmo) }\end{array}$ & $\begin{array}{l}\text { PhD. En Sociología } \\
\text { (Universidad de Estocolmo) }\end{array}$ \\
\hline 17. Ricardo Paredes & $\begin{array}{l}\text { Ingeniería comercial } \\
\text { (Universidad de Chile) }\end{array}$ & $\begin{array}{l}\text { PhD. En Economía } \\
\text { (Universidad de California) }\end{array}$ \\
\hline 18. Marcela Ríos & $\begin{array}{l}\text { Sociología (Universidad de } \\
\text { York) }\end{array}$ & $\begin{array}{l}\text { PhD. En Ciencia Política } \\
\text { (Universidad de Wisconsin- } \\
\text { Madison) }\end{array}$ \\
\hline 19. Claudia Robles & $\begin{array}{l}\text { Sociología (Pontificia } \\
\text { Universidad Católica de } \\
\text { Chile) }\end{array}$ & $\begin{array}{l}\text { PhD. En Sociología } \\
\text { (Universidad de Essex) }\end{array}$ \\
\hline 20. José Luis Ruiz & $\begin{array}{l}\text { Ingeniería comercial } \\
\text { (Universidad de Chile) }\end{array}$ & $\begin{array}{l}\text { PhD. En Economía } \\
\text { (Universidad de } \\
\text { Pennsylvania) }\end{array}$ \\
\hline 21. Claudia Sanhueza & $\begin{array}{l}\text { Ingeniería comercial } \\
\text { (Universidad de Chile) }\end{array}$ & $\begin{array}{l}\text { PhD. En Economía } \\
\text { (Universidad de Cambridge) }\end{array}$ \\
\hline 22. Jorge Tarziján & $\begin{array}{l}\text { Ingeniería comercial } \\
\text { (Pontificia Universidad } \\
\text { Católica de Chile) }\end{array}$ & $\begin{array}{l}\text { PhD. En Economía } \\
\text { (Universidad de } \\
\text { Northwestern) }\end{array}$ \\
\hline 23. Sergio Urzúa & $\begin{array}{l}\text { Ingeniería comercial } \\
\text { (Universidad de Chile) }\end{array}$ & $\begin{array}{l}\text { PhD. En Economía } \\
\text { (Universidad de Chicago) }\end{array}$ \\
\hline 24. Andras Uthoff** & $\begin{array}{l}\text { Ingeniería comercial } \\
\text { (Universidad de Chile) }\end{array}$ & $\begin{array}{l}\text { PhD. En Economía } \\
\text { (Universidad de Berkeley) }\end{array}$ \\
\hline
\end{tabular}

*En Chile, a nivel de pregrado, se homologa la carrera de Ingeniería Comercial a la de Economía.

**Partícipes también de la Comisión Marcel (2006).

Fuente: Elaboración propia sobre la base de Informe final (CAP, 2015).

Un análisis detallado de las propuestas generadas por la comisión hacia el gobierno revela que solo siete de ellas consisten en transformaciones sustantivas al sistema de pensiones chileno, pues implican terminar con la capitalización individual e introducen la solidaridad, desconcentran la inversión de los fondos, proponen una AFP estatal 
que no lucra con el derecho social previsional y unifican el sistema de pensiones para los civiles con los miembros de las FF.AA. y de orden. Por su parte, las cincuenta restantes pueden clasificarse en la categoría de ajustes dentro del sistema vigente. Respecto de la propuesta global que buscaba el paso desde un sistema de capitalización individual hacia uno de reparto, el presidente de la instancia declaró que "es una opción que debe descartarse, creo que hay que decirlo claramente: debe descartarse. Es un sistema que no es sustentable, no es viable" (Berríos y Lefin, 2018), lo que junto con la votación final —en donde esta opción solo alcanzó una preferencia-, da cuenta del espectro limitado de alternativas efectivamente presentes en las discusiones de la comisión. Nuevamente, el trabajo de instancias de este tipo viene a consolidar el dominio neoliberal, asegurando su continuidad, pues se prefiere mantener su núcleo mediante la inclusión de ajustes, antes que realizar transformaciones.

Entre los ajustes propuestos, destacan la cotización con cargo al empleador que se destinará a un fondo solidario, rompiendo con la lógica de capitalización individual; la creación de instrumentos de inversión nacional productiva, que apunta a desconcentrar la inversión en los grandes grupos económicos; la creación de una AFP estatal, que no responde a la lógica del lucro con un derecho social; y por último, la progresiva asimilación del sistema solidario paralelo de las fuerzas armadas y de orden en el sistema de capitalización individual, el que culminaría con el sistema paralelo en que actualmente se encuentran estas instituciones (CAP, 2015). No obstante, se observa que entre las propuestas existen potenciales aperturas a cambios a nivel paradigmático, o de tercer orden (Hall, 1993), ellas aún no acumulan la influencia suficiente para desbancar al principio de capitalización individual y a la posibilidad de lucro como objetivos jerárquicos del sistema previsional.

Sin perjuicio de estas propuestas - entre las cuales solo la creación de un fondo solidario ha prosperado-, lo que primó en la labor de la Comisión Bravo fue un trabajo que desde la ciencia apostó por capturar el interés común, con una visión social poco pluralista, dentro de un esquema de trabajo racionalista que intentó prever procedimentalmente los resultados del sistema de pensiones, sin una discusión democrática ampliada. Esta situación releva el problema de incompa- 
tibilidad de instancias técnicas para hacer frente a temas eminentemente políticos, como lo es el sistema de pensiones que una sociedad implementa para sí. Se trata, en definitiva, de problemas políticos con componentes técnicos, y no al contrario, como se ha querido presentar en Chile en estas instancias, pudiendo generar eventuales sensaciones en los votantes de que los gobiernos evaden responsabilidades políticas, justificando decisiones de esa naturaleza mediante argumentos técnicos.

Sin embargo, y a la luz de las declaraciones de Andras Uthoff, el problema tiene una capa adicional de complejidad. Según el testimonio del consejero, la votación por las propuestas se ejecutó cuando la comisión no tenía conocimiento cabal de las propuestas: "Déjeme serle franco, no le puedo hacer juicios sobre la [propuesta] A porque nunca la expusieron en su totalidad" (Urquieta, 2015). Es decir, en la instancia crucial de esta comisión técnica, lo que prevalecieron fueron intereses políticos, pues sus consejeros no tenían total conocimiento de lo que estaban votando. Esta situación devela una de las principales características de la representación tecnocrática: se trata de una que sí cobija intereses políticos, aunque negados en nombre de la neutralidad técnica y la búsqueda de eficiencia económica. Y es en nombre de estos principios que la deliberación democrática extendida es negada, al igual que el control ciudadano sobre los tecnócratas.

\section{Conclusiones}

Este artículo ha indagado en las características y el funcionamiento de las CAP para la reforma previsional de 2006 y 2015, como ejemplos de instancias que capturaron bajo una lógica de representación tecnocrática demandas que buscaron impugnar el funcionamiento del neoliberalismo en Chile. En efecto, tanto en 2006 como en 2015 hubo manifestaciones ciudadanas respecto de la insuficiencia del sistema de pensiones privado para entregar protección social, especialmente para los estratos sociales de menor ingreso. Bajo el aura de la razón técnica fundamentada científicamente, las comisiones funcionaron sustrayendo un tema eminentemente político de la arena democrática, en este caso, el sistema previsional que una sociedad se dará a sí mismo, para procesarlo en un espacio de escaza pluralidad e intentar legitimar sus recomendaciones en función del saber experto. 
Esta captura de asuntos políticos a manos de la tecnocracia, en nombre de la eventual primacía de los aspectos técnicos que contiene, se consolida al observar la composición de las comisiones. En su mayoría, fueron hombres (67\%), que estudiaron su pregrado en la Universidad de Chile o en la Pontificia Universidad Católica de Chile (74\%), con formación en Economía a nivel de pregrado (67\%) y posgrado (69\%). Esta situación va en línea con la comprensión de la economía en su perspectiva neoclásica, como la profesión más característica de los tecnócratas (Markoff y Montecinos, 1993), quienes suelen entregar recomendaciones en forma de soluciones de inspiración técnico-científicas a problemas de naturaleza política, que resultan ajenos a su área de expertise, lo que los convierte en actores irremplazables para evaluar desde la presunta neutralidad científica todo lo concerniente al proceso decisional de políticas públicas $(\mathrm{Ru}-$ mié, 2019).

El anotado dominio de economistas en estas instancias - quienes en su mayoría se han formado en universidades estadounidenses (51\%) pertenecientes a las corrientes principales de la disciplina-, tiene como consecuencia una reducción del horizonte transformador de los principios neoliberales. La evaluación de las recomendaciones de ambas comisiones así lo demuestra, pues ellas no apuntan a transformar el núcleo neoliberal que anima el funcionamiento del sistema de pensiones chileno, sino que lo apuntalan mediante un rol subsidiario del Estado, manteniendo incólumes la preponderancia del mercado y la responsabilidad individual previsional.

Es así como mediante la introducción de sucesivos ajustes al funcionamiento del esquema previsional neoliberal, los cuales no proponen transformaciones a los principios según los cuales funciona, que la razón tecnocrática aporta en su mantención y resiliencia frente a desafíos políticos reformistas.

Esta experiencia remite a un fenómeno más complejo de afinidad entre la tecnocracia y el neoliberalismo. Ambos regímenes de poder coinciden en la superioridad del mercado como asignador de bienes y servicios respecto de cualquier otro sistema de ordenamiento social. La confluencia se refuerza a través de una minusvaloración compartida de la democracia cuya soberanía, se arguye, debe ser restringida en el área económica, pues esta antes que ser gobernada por la agrega- 
ción irracional de preferencias ciudadanas, debe regirse en función del conocimiento experto con fundamentos científicos.

El área previsional no es el único ejemplo de resiliencia neoliberal en Chile. Desde la recuperación de la democracia en 1990, cada vez que se ha cuestionado el funcionamiento del neoliberalismo en áreas sociales cruciales, como la salud y la educación, el sistema político ha optado por acoger esas críticas y procesarlas mediante una arquitectura institucional de representación tecnocrática. Tanto es así que todos los gobiernos democráticos han recurrido a CAP para tramitar demandas sociales reformistas de los principios neoliberales que animan el funcionamiento general de la economía y los servicios públicos. La decreciente legitimidad del saber experto ha sido suficiente, al menos hasta la actualidad, para funcionar como pilar de la continuidad del neoliberalismo en Chile. Resta evaluar, sin embargo, las implicancias de este aspecto en el estallido social de octubre 2019 que, aunque difusamente, emergió a modo de impugnación a varios fundamentos neoliberales que ordenan a la sociedad chilena.

Al cierre de esta investigación, se promulgó la ley que permite el retiro de hasta el $10 \%$ de los fondos previsionales de los afiliados al sistema AFP. Esta medida cataliza dos breves reflexiones. En primer lugar, significa un episodio de ruptura entre el saber técnico y la conducción política en asuntos macroeconómicos. Pese al consenso tecnocrático respecto de la conveniencia de optar por herramientas alternativas para enfrentar la crisis económica producida por la pandemia Covid-19, como créditos subsidiados y contingentes al ingreso, la iniciativa prosperó con un apoyo político transversal. En momentos de repolitización y alta intensidad de la democracia, y especialmente de cara al futuro más próximo, la tecnocracia pierde peso relativo en la arquitectura institucional decisional. En segundo lugar, puede advertirse un triunfo neoliberal, pues se optó por subsanar los efectos de la crisis bajo una lógica individual y competitiva antes que colectiva y solidaria. Precisamente, uno de los mayores éxitos de la ideología neoliberal consiste en devenir inadvertida y naturalizada, como si no existiesen alternativas viables.

\section{Referencias}

Aguilera, C. (mayo de 2009). Un análisis de las comisiones asesoras presidenciales del Gobierno de Bachelet. FLACSO-Chile. http:// 
flacsochile.org/wp-content/uploads/2015/05/Un-Analisisde-las-comisiones-asesoras-presidenciales-del-gobiernode-Michelle-Bachelet.pdf

Aguilera, C. y Fuentes, C. (2011). Elites y asesoría experta en Chile: comisiones y políticas públicas en el gobierno de Bachelet. En A. Joignant y P. Güell (Eds.), Notables, tecnócratas y mandarines (pp. 127-151). Ediciones Universidad Diego Portales, UDP.

Akram, H. (2020). El estallido. Ediciones y Publicaciones El Buen Aire.

Atria, F. (2013). Veinte años después. Neoliberalismo con rostro humano. Catalonia.

Bellei, C. (2015). El gran experimento: mercado y privatización de la educación chilena. LOM ediciones.

Berríos, M. y Lefin, D. (21 de abril de 2018). David Bravo, sobre reparto: "Solo en sueños se puede generar una pensión a cambio de nada". El Mercurio. http://www.economiaynegocios.cl/noticias/noticias.asp?id=461982

Biglaiser, G. y Brown, D. (2003). The determinants of privatization in Latin America. Political Research Quarterly, 56(1), 77-89. https://doi.org/10.1177/106591290305600108

Brown, M. (2009). Science in democracy: Expertise, institutions, and representation. Massachusetts Institute of Technology, MIT Press.

Brown, W. (2015). Undoing the demos. Neoliberalism's stealth revolution. Zone Book.

Buchanan, J. (1979). What should economists do? Liberty Press.

Caramani, D. (2017). Will vs. reason: The populist and technocratic forms of political representation and their critique to party government. American Political Science Review, 111(1), 5467. https://doi.org/10.1017/s0003055416000538

Castiglioni, R. (2018). Explaining uneven social policy expansion in democratic Chile. Latin American Politics and Society, 60(3), 54-76. https://doi.org/10.1017/lap.2018.24

Centeno, M. A. y Wolfson, L. (1997). Redefiniendo la tecnocracia. Desarrollo Económico, 146(37), 215-40. https://doi. org $/ 10.2307 / 3467196$

Cisternas, C. y Vásquez, J. (2018). Comisiones asesoras presidenciales en Chile: entre la expertise y la pluralidad de actores sociales. 
Revista Europea de Estudios Latinoamericanos y del Caribe, (106), 1-22. https://doi.org/10.32992/erlacs.10349

Collier, D. (2011). Understanding process tracing. Political Science and Politics, 44(4), 823-30. https://doi.org/10.1017/ s1049096511001429

Comisión Asesora Presidencial sobre el sistema de pensiones. (2006). $E l$ derecho a una vida digna en la vejez. Hacia un contrato social con la previsión en Chile. https://www.previsionsocial.gob. cl/sps/download/estudios-previsionales/comisionpensiones/documentos-interes-general/informe-consejo-asesorpresidencial-reforma-del-sistema-previsional-comisionmarcel-2006.pdf

Comisión Asesora Presidencial sobre el sistema de pensiones. (2015). Informe final. https://prensa.presidencia.cl/lfi-content/ otras/informes-comisiones/InformePensiones.pdf

Crouch, C. (2011). The strange non-death of neoliberalism. Polity Press.

Dargent, E. (2015). Technocracy and democracy in Latin America: The experts running governments. Cambridge University Press.

Davies, W. (2014). The limits of neoliberalism: Authority, sovereignty and the logic of competition. Sage.

Decreto Presidencial No 718 Crea Comisión Asesora Presidencial sobre el Sistema de Pensiones del Ministerio de Hacienda. Diario Oficial de la República de Chile, 24 de abril de 2014.

Delamaza, G. (2010). Conflicto político y diseños institucionales de participación en el caso chileno. Revista de Sociología, (23), 11-37. https://doi.org/10.5354/0719-529x.2010.27505

El Mercurio. (4 de febrero de 2000). Chilenos se pensionarían con el $100 \%$ de su sueldo el 2020. El Mercurio.

Espacio Público-IPSOS. (2019). Encuesta Movilización 2019. https:// www.espaciopublico.cl/wp-content/uploads/2019/12/ ENCUESTA-MOVILIZACIONES-2019_ESPACIOPUBLICOIPSOS.pdf

Ffrench-Davis, R. (2018). Reformas económicas en Chile, 1973-2017. Taurus.

Fisher, F. (2009). Democracy and expertise. Reorienting policy inquiry. Oxford University Press.

Fisher, M. (2017). Realismo capitalista. ¿No hay alternativa? Caja Negra. 
Fishman, R. (2016). Rethinking dimensions of democracy for empirical analysis: Authenticity, quality, depth and consolidation. Annual Review of Political Science, 19(1), 289-309. https://doi. org/10.1146/annurev-polisci-042114-015910

Foucault, M. (2008). Nacimiento de la biopolítica. Fondo de Cultura Económica.

Friedman, M. (1951). Neo-liberalism and its prospects. Farmand, (17), 89-93.

Friedman, M. (1962). Capitalism and freedom. The University of Chicago Press.

Gálvez, R. y Kremerman, M. (2020). ¿AFP para quién? Dónde se invierten los fondos de pensiones en Chile. Fundación Sol.

Gárate, M. (2012). La revolución capitalista de Chile (1973-2003). Ediciones Universidad Alberto Hurtado.

Garretón, M., Cruz, M., y Aguirre, F. (2012). La experiencia de los consejos asesores presidenciales en Chile y la construcción de los problemas públicos. Revista Mexicana de Sociología, 74(2), 303-340. https://www.jstor.org/stable/43495613?seq=1

Geddes, B. (2003). Paradigms and sandcastles: Theory building and research design in comparative politics. University of Michigan Press.

Hall, P. (1993). Policy paradigms, social learning, and the state: The case of economic policymaking in Britain. Comparative Politics, 25(3), 275-296. https://doi.org/10.2307/422246

Harvey, D. (2007). Breve historia del neoliberalismo. Akal.

Hayek, F. (1960). The constitution of liberty. University of Chicago Press.

Hayek, F. (1980). Camino de servidumbre. Alianza.

Huneeus, C. (2014). La democracia semisoberana. Chile después de Pinochet. Taurus.

Huneeus, C. (2016). El régimen de Pinochet. Taurus.

Huntington, S. (1972). El orden político en las sociedades en cambio. Paidós.

Joignant, A. (2012). La razón de Estado: usos políticos del saber y gobierno científico de los technopols en Chile (1990-1994). En T. Aristía (Ed.), Produciendo lo social. Usos de las ciencias sociales en el Chile reciente (pp. 311-328). Ediciones de la Universidad Diego Portales, UDP. 
Joignant, A. y Güell, P. (2011). Poder, dominación y jerarquía: elementos de sociología de las elites en Chile (1990-2010). En A. Joignant y P. Güell (Eds.), Notables, tecnócratas y mandarines (pp. 1121). Ediciones de la Universidad Diego Portales, UDP.

Laclau, E. y Mouffe, C. (1985). Hegemony and socialist strategy. Towards a radical democratic politics. Verso.

Latinobarómetro. (1998). Banco de datos. http://www.latinobarometro.org/latContents.jsp

Latinobarómetro. (2008). Banco de datos. http://www.latinobarometro.org/latContents.jsp

Laval, C. y Dardot, P. (2013). La nueva razón del mundo. Ensayo sobre la sociedad neoliberal. Gedisa.

Lazzarato, M. (2020). El capital odia a todo el mundo. Eterna Cadencia.

Lechner, N. (1998). Modernización y democratización: un dilema del desarrollo chileno. Estudios Públicos, (70), 231-242. https://www.cepchile.cl/cep/site/ docs/20160303/20160303183738/rev70_lechner.pdf

Madariaga, A. (2020). The three pillars of neoliberalism: Chile's economic policy trajectory in comparative perspective. Contemporary Politics, 26(3), 308-329. https://doi.org/10.1080/135697 75.2020 .1735021

Maillet, A. (2015). Variedades de neoliberalismo. Innovación conceptual para el análisis del rol del Estado en los mercados. Revista de Estudios Políticos, (169), 109-36. https://doi. org/10.18042/cepc/rep.169.04

Markoff, J. y Montecinos, V. (1993). The ubiquitous rise of economists. Journal of Public Policy, 13(1), 37-68. https://doi. org/10.1017/s0143814x00000933

Mascareño, A. (2010). Coordinación social mediante políticas públicas: el caso chileno. Revista de la CEPAL, (101), 111-26. https://doi.org/10.18356/c2895a7c-es

Mirowski, P. y Plehwe, D. (Eds.) (2009). The road from Mont Pèlerin. The making of the neoliberal thought collective. Harvard University Press.

Mizala, A. y Romaguera, P. (2001). La legislación laboral y el mercado del trabajo: 1975-2000. En R. Ffrench-Davis y B. Stallings (Eds.), Reformas, crecimiento y politicas sociales en Chile desde 1973 (pp. 201-230). LOM ediciones. 
Olivares, A. y Carrasco, C. (2020). Social movements and public policies in Chile: Analysis of the Student Movement of 2011 and the No+AFP movement of 2016. Romanian Political Science Review, 20(2), 203-222. https://www.ssoar.info/ssoar/bitstream/handle/document/69926/ssoar-sp-rpsr-2020-2-olivares_et_al-Social_Movements_and_Public_Policies.pd $\mathrm{f}$ ? sequence $=1$ \&isAllowed $=\mathrm{y} \& \ln k n a m e=$ ssoar - sp - rpsr2020-2-olivares_et_al-Social_Movements_and_Public_Policies.pdf

Osorio, C. (2018). Formulación de políticas públicas en Chile. En C. Huneeus y O. Avendaño (Eds.), El sistema político de Chile (pp. 301-332). LOM ediciones.

Piñera, J. (1991). La revolución laboral en Chile. Zig-Zag.

Przeworski, A. (1992). The neoliberal fallacy. Journal of Democracy, 3(3), 45-59. https://doi.org/10.1353/jod.1992.0044

Ramírez, S. (2020). Constitución chilena y gubernamentalidad neoliberal. Derecho y crítica social, 5(1-2), 82-121. https://derechoycriticasocial.files.wordpress.com/2020/04/3.pdf

Rivadeneira, C. (2017). Aquí se fabrican pobres. El sistema privado de pensiones chileno. LOM ediciones.

Rozas, J. y Maillet, A. (2019). Entre marchas, plebiscitos e iniciativas de ley: innovación en el repertorio de estrategias del movimiento No Más AFP en Chile (2014-2018), Izquierdas, (48), 1-21. https://dx.doi.org/10.4067/S0718-50492019000400001

Ruiz, C. (2019). La política en el neoliberalismo. Experiencias latinoamericanas. LOM ediciones.

Ruiz, C. (2020). Octubre chileno. Taurus.

Ruiz, C. y Boccardo, G. (2014). Los chilenos bajo el neoliberalismo. El Desconcierto-NodoXXI.

Rumié, S. (2019). Chicago boys en Chile: neoliberalismo, saber experto y el auge de una nueva tecnocracia. Revista Mexicana de Ciencias Políticas y Sociales, 64(235), 139-164. http://dx.doi. org/10.22201/fcpys.2448492xe.2019.235.61782

Salazar, G. (2019). El Ejército de Chile y la soberanía popular. Debate.

Sánchez-Cuenca, I. (2020). Neoliberal technocracy. En E. Bertsou y D. Caramani (Eds.), The Technocratic challenge to democracy (pp. 44-60). Routledge.

Schumpeter, J. (1983). Capitalismo, socialismo y democracia. Orbis. 
Silva, P. (2010). En el nombre de la razón: tecnócratas y política en Chile. Ediciones de la Universidad Diego Portales, UDP.

Silva, P. (2012). Tecnócratas y política en Chile: de los Chicago boys a los Monjes de Cieplan. En T. Aristía (Ed.), Produciendo lo social. Usos de las ciencias sociales en el Chile reciente (pp. 73-100). Ediciones de la Universidad Diego Portales, UDP.

Solimano, A. (2012). Chile and the neoliberal trap. The post Pinochet Era. Cambridge University Press.

Sousa Santos, B. (Coord.) (2004). Democratizar la democracia. Los caminos de la democracia participativa. Fondo de Cultura Económica.

Stallings, B. (2001). Las reformas estructurales y el desempeño económico. En R. Ffrench-Davis y B. Stallings (Eds.), Reformas, crecimiento y políticas sociales en Chile desde 1973 (pp. 23-60). LOM ediciones.

Streeck, W. (2014). Buying time: The delayed crisis of democratic capitalism. Verso.

Toro, S. (2007). Conducta legislativa ante las iniciativas del Ejecutivo: unidad de los bloques políticos en Chile. Revista de Ciencia Política (Santiago), 27(1), 23-41. http://dx.doi.org/10.4067/ S0718-090X2007000200002

Urquieta, C. (28 de septiembre de 2015). Miembro de la comisión Bravo devela cómo se intentó quitar piso a la propuesta que cambia estructuralmente el sistema de AFPs. El Mostrador. https://m. elmostrador.cl/noticias/pais/2015/09/28/miembro-de-la-comision-bravo-devela-como-se-intento-quitar-piso-a-la-propuesta-que-cambia-estructuralmente-el-sistema-de-afps/

Uthoff, A. (2001). La reforma del sistema de pensiones y su impacto en el mercado de capitales. En R. Ffrench-Davis y B. Stallings (Eds.), Reformas, crecimiento y politicas sociales en Chile desde 1973 (pp. 231-262). LOM ediciones.

Valdés, J. G. (1995). Pinochet's economists. The Chicago School in Chile. Cambridge University Press.

Weber, M. (2012). El político y el científico. Alianza. Original publicado en 1919.

Weyland, K. (1999). Economic policy in Chile's new democracy. Journal of Interamerican Studies and World Affairs, 41(3), 67-96. https://doi.org/10.2307/166159 
Zegart, A. (2004). Blue ribbons, black boxes: Toward a better understanding of presidential commissions. Presidential Studies Quarterly, 34(2), 366-393. https://doi.org/10.1111/j.17415705.2004.00049.x 